\title{
Rewriting the call to charity: From food shelf volunteer to food justice advocate
}

\author{
Beth A. Dixon ${ }^{\text {a }}$ \\ State University of New York College at Plattsburgh
}

Submitted September 1, 2014 / Revised November 25, 2014, and January 1 and January 8, 2015 /

Accepted January 9, 2015 / Published online February 22, 2015

Citation: Dixon, B. A. (2015). Rewriting the call to charity: From food shelf volunteer to food justice

advocate. Journal of Agriculture, Food Systems, and Community Development, 5(2), 71-79.

http://dx.doi.org/10.5304/jafscd.2015.052.010

Copyright (C) 2015 by New Leaf Associates, Inc.

\begin{abstract}
Consider the food shelf volunteer (or any charity worker) who is inspired to practice good work on behalf of those who are poor and hungry. Her beneficence is praiseworthy. But a simple call to charity may also blind the volunteer to certain facts about food justice. First, it leaves out why clients who utilize the food shelf are hungry. Second, it suggests that the generous volunteers who staff the food shelf have met their political responsibilities. In this viewpoint I argue that hunger relief advocates may be transformed into policy advocates only if they are epistemically positioned to do so. What we need is a new practical strategy or technique for rewriting the very nature of what it means to engage in charity. This strategy involves using stories or narratives that profile particular people who are food insecure, but that also include

a Beth A. Dixon, Department of Philosophy, State University of New York College at Plattsburgh; Champlain Valley Hall 0306; Plattsburgh, New York 12901 USA; +1-518-564-2836; beth.dixon@plattsburgh.edu
\end{abstract}

systemic background conditions describing the social, political, and economic positions of more than one person. To make visible these background conditions I employ the philosophical concept of a "counterstory." Counterstories reveal structural inequities that identify how groups of people are unfairly disadvantaged. Acquiring this point of view is necessary for undertaking our collective responsibilities for achieving food justice because it positions us to see what structural conditions must change. In this way food justice activism becomes a real goal, made possible by the creation of a knowledgeable and informed citizenry.

\section{Keywords}

charity, food justice, moral responsibility, activism, narratives

\section{Political Responsibility and Knowledge}

The sign above the entrance to the Interfaith Food Shelf reads, "I was hungry and you gave me food." There is no doubt that this religious evocation is 
inspirational for most of the volunteers who help distribute emergency food to members of our local community. But this simple call to charity also blinds us to certain facts about food justice. First, it leaves out $w h y$ these individuals who visit the food shelf are hungry. And second, it suggests that the generous volunteers who staff the food shelf (and others) have met their political responsibilities by engaging in charity work. But as Young (2011) argues, the issue of our respective responsibility for justice is more complicated:

We should also ask whether and how we contribute by our actions to structural processes that produce vulnerabilities to deprivation and domination for some people who find themselves in certain positions with limited options compared to others. (p. 73)

If Young's argument-that individual citizens have a responsibility to alleviate social and political injustice-is plausible, then we should ask how to best epistemically position the volunteer. One obstacle that interferes with transforming ordinary citizens into policy advocates is lack of knowledge about systemic injustices that unequally oppress and constrain the choices of individuals who are attempting to live well. In this viewpoint essay I argue that what we need is a new practical strategy or technique for revealing the structural conditions that more fundamentally explain the causes of poverty and hunger. This practical strategy involves using stories or narratives that profile particular people who are food insecure, when these stories in addition include descriptions of social, political, and economic background conditions of more than one person. To this end I borrow the concept of a counterstory (Nelson, 2001). By reading, watching, or even writing a counterstory, the volunteer, ordinary citizen, or student becomes alert to a way of seeing structural inequities that position some groups of people to unfair disadvantage. Acquiring this point of view is necessary for undertaking our collective responsibilities for achieving food justice, because it positions us to see what structural conditions must change.

\section{The Food Justice Lens}

The tensions existing between food justice advocates and hunger relief advocates are well documented in much of the literature about alternative food movements. For example, Gottlieb and Joshi (2010) identify the need to redescribe hunger as an issue about economic justice in such a way as to transform earnest and motivated food shelf volunteers into policy advocates. Winne (2008) and HoltGiménez (2011) both urge an alliance between the charity worker and the food justice advocate. In particular, Winne (2008) laments that even though food banks and charity work attract the attention of many influential people, rarely do those people participate in public policy discourse about poverty and hunger. Holt-Giménez (2011) remarks that, "Where one stands on hunger depends on where one sits" (p. 319). He recommends a "radical" approach to food justice issues that targets structural changes in the food system, creating opportunities for increased equity in land ownership and working towards a redistribution of wealth. But as Holt-Giménez reminds us, what we also need in order to advance such large-scale systematic policy changes are coalitions between those who are working for underserved populations, and those who are directly involved with the structural transformation of our food system.

Allen (2010) suggests that local food movements can aspire to food justice goals by (a) increasing understanding of structural conditions, (b) analyzing local food priorities and activities, and (c) evaluating criteria for social justice (pp. 297300). She also emphasizes the need for structural change in the form of public policy, citing Gutierrez (1995) on the importance of changing beliefs and attitudes to work toward social change by developing a sense of what she calls "critical consciousness." Allen and Guthman (2006) claim that the priority of alternative food movements must involve changing policies and economic patterns, rather than merely making better personal choices. And Guthman (2008) urges more structural activism about inequity.

What will facilitate this shift in focus in the direction of social and political change? Guthman (2008) recommends that we move toward a politics of "listening, watching, and not always helping" 
(p. 443). Sbicca's (2012) case study of People's Grocery examined how this food justice organization addresses food justice goals in order to mobilize volunteers to target the structural causes of hunger and poverty. Sbicca's research reveals that one problem facing People's Grocery, in particular, is finding an ideological underpinning to support the mobilization of these activists' efforts. Hassanein (2003) argues persuasively that to achieve even incremental change in the food system requires the method of food democracy, which depends on an informed citizenry and a deeper engagement by ordinary citizens. Additionally, Gilson (2014) argues that the citizenconsumer has political responsibilities for food justice beyond merely "voting with her fork" (p. 113) These responsibilities extend to "interrogating the political-economic structures that are part of the normal conditions of the industrial, global food system" (p. 14). But in order to envision what ought to be done, ordinary citizens need also to reevaluate assumptions about personal responsibility.

Regarding issues of food insecurity, the need for political and structural change is clearly identified by all these writers. But we might still want to know how to implement these suggestions practically in order to increase understanding of structural conditions, or how best ordinary citizens should become informed, or bow they will develop a critical consciousness. One overlooked aspect of the food justice lens is determining what ordinary citizens should know in order to develop tactics and strategies for bringing about justice. This is an epistemic obstacle that must be overcome before we can expect that volunteers at the food pantry, for example, can transform into policy advocates. This is especially problematic for those who do charity work on behalf of the hungry, since they must be able to see beyond the culturally entrenched idea that charity is the solution to hunger. Poppendieck (1998) describes the "moral safety valve" (p. 8) function of charitable organizations that feed the hungry, which is the idea that by donating time, food, or money to various kinds of emergency food programs, we relieve ourselves of the need to work on changing the more funda- mental causes of poverty. ${ }^{1}$ In the next section I describe another kind of epistemic obstacle to food justice advocacy. This involves identity-constituting narratives of those who are food insecure.

\section{The Personal Responsibility Script}

Young (2011) writes that in the last two decades we have seen a shift in the discourse about those who are poor. This discourse implies that the causes of poverty and hunger depend on the characteristics and behavior of the poor themselves. One way of describing this "deviant" behavior is that those living on the margins of our society fail to exhibit a sufficient degree of personal responsibility for their lives. This purported lack of responsibility is used to explain how some, but not others, have become poor and dependent on social service programs. This way of thinking and talking about those who are in poverty is pervasive in a variety of settings, some of which I will examine below. By virtue of its rhetorical power this kind of discourse qualifies as a "master narrative" that explains why individual people are hungry.

Nelson (2001) characterizes master narratives as "stories found lying about in our culture that serve as summaries of socially shared understandings...often archetypal, consisting of stock plots and readily recognizable characters types" (p. 6) that we use to make sense of our experiences, and which inform our moral intuitions. In this case the master narrative about why individuals are hungry might be articulated in the following way: those who are food insecure are personally responsible for their plights. These individuals may have made wrong choices, or perhaps they have not tried hard enough to provide for themselves and their families. Still it is not inconsistent with this characterization to participate in food charity. For example, Poppendieck (1998) writes that charity is an appro-

\footnotetext{
${ }^{1}$ On a similar theme, Poppendieck (1998) describes the

"[King] Wenceslas syndrome" in the following way:
}

The process by which the joys and demands of personal charity divert us from more fundamental solutions to the problems of deepening poverty and growing inequality, and the corresponding process by which the diversion of our efforts leaves the way wide open to those who want more inequality, not less. (p. 19) 
priate response to hunger since charity involves giving to people who are "not like us" (p. 306), and as income inequalities increase the poor seem even more different from those who are economically comfortable.

Another version of this master narrative about food insecurity is that hunger is the outcome when someone has suffered some tragic accidental misfortune that interfered with his or her ordinary ability to take full responsibility for his or her life. The salient feature of both versions of this master narrative is that they appear to explain the complex social conditions of food insecurity by reference to individuals and by reference to the idiosyncratic actions or events that surround their particular lives. This kind of master narrative is best described as the "personal responsibility script" (Brownell \& Warner, 2009, p. 266).

The personal responsibility script is misleading about the causes of hunger. It gains a certain amount of traction as a plausible explanation, however, because in fact it represents some partial truths about the world. It is true that some people who use food stamps may not want to work, for example. And it is also true that some people who are hungry are in this predicament because they have suffered accidental misfortunes for which they themselves cannot be blamed. But the main problem with the personal responsibility script is that it is incomplete, and by virtue of its incompleteness it misrepresents some more fundamental conditions about hunger and poverty that explain how populations of people, as opposed to individuals, are similarly and unjustly disadvantaged by virtue of occupying the same social and political "position."

Why does this matter? Nelson (2001) describes how identities can be damaged by master narratives, contributing to the oppression of individual people or the subgroups to which they belong. One of the ways oppressive master narratives can damage identities is by deprivation of opportunity, when a master narrative imposes a degrading identity on a person or a group, characterizing them as morally subnormal or abnormal. When oppressive master narratives find their way into public policy debates about Supplemental Nutrition Assistance Program (SNAP) benefits, for example, what hangs in the balance is the very real possibility that those who are food insecure may suffer a serious deprivation of opportunity to nourish themselves. For example, consider Representative Steven Fincher, a Republican congressman from Dyersburg, Tennessee, elected in 2010 by tea party constituents.

Between 1999 and 2012, Fincher collected close to US $\$ 3.5$ million in farm subsidies for corn and soybeans from the federal government. He recently voted for a farm bill that omitted SNAP benefitsa position he defended by stating, "The role of citizens, of Christianity, of humanity, is to take care of each other, not for Washington to steal from those in the country and give to others in the country" (Stolberg, 2013, p. A1). In response to a Democrat who invoked the Bible during the food stamp debate in Congress, Fincher cited his own biblical phrase: "The one who is unwilling to work shall not eat" (Stolberg, 2013, p. A1). ${ }^{2}$ Fincher's remarks capture a presumed general truth that many accept, especially if there is no countervailing reason to believe otherwise. The presumed truth is that the recipients of charity owe their food insecurity to individual choices, in particular to the choice not to work. Essentially, those who are food insecure are personally responsible for the plight in which they find themselves.

A variation on the personal responsibility script emerges also from those who advocate for hunger relief. The website feedingamerica.org of the Feeding America network of food banks collects and publicizes research and statistics about hunger in America (Feeding America, 2014). It also reveals the "faces" of hunger by profiling real stories of actual people who are hungry. These are accompanied by pictures of those who use food stamps or are forced to accept food at a food shelf, and sometimes include short videos of the family. These stories are fascinating as much for the information included as for what they leave out. For example, the story of Marvin, a Georgia resi-

\footnotetext{
2 Poppendieck (1998) notes that many of the people who participate in charitable food programs are motivated to do so for religious beliefs. She remarks, "The emergency food system is permeated with religion. More than 70 percent of the pantries and kitchens affiliated with the Second Harvest Network are sponsored by churches or other religious organizations" (pp. 188-189).
} 
dent 51 years old, begins with his loss of hearing as a child, and the gradual loss of his vision as an adult. Devoted to finding work even though he does not see well, he is forced to seek menial labor such as washing windows or mowing lawns. But then he is hit by a car, and now he is unable to work at all, though he still strongly desires to do so. Marvin hopes that he will eventually "get back on his feet." In the meantime he is grateful for receiving food stamps because they keep him from going hungry.

Marvin's story elicits sympathy from us largely because it is about how bad luck can bring a person down. Significantly, the conditions that impede Marvin from working are illnesses and accidents for which he is not to be blamed. This allows us to see him as an agent who has all the right motivational states for living a better life: he wants to work. But at the same time his actions are constrained by circumstances out of his control. His inability to work and thus to feed himself is shaped by these contingencies. The reader of this story senses that if life had dealt Marvin a slightly different hand, then he would surely make good on his responsibility to provide food for himself.

Each version of the personal responsibility script illustrated here is a damaging master narrative about who is hungry and why. They are damaging in the sense that each kind of story interferes with an ordinary citizen's understanding of the need for advocacy and justice, although in slightly different ways. In the first case, if we accept that the poor and hungry are essentially different than us and in some way morally at fault, then we will see this inequality as a natural outcome of poor choices or as a failure of moral character. We may pity those who are hungry and continue to feed them through acts of charity, but we may not believe that changes in public policy and advocating for political justice are necessary because in these cases it is not deserved. Alternatively, individual stories like those of Marvin that reveal the "faces" of hunger demonstrate that under normal circumstances most of us can realize our responsibilities to work and thus to feed ourselves. Nevertheless, these ordinary circumstances sometimes go awry, creating obstacles to living well through no fault of those individuals who suffer the consequences. In fact, we may well imagine that life could have gone the same way for any one of us: a series of unfortunate events due to illness and accidents that create obstacles to living well. In this account of things we may believe that those who suffer food insecurity are morally deserving. But this kind of master narrative preserves our inclinations to extend food charity in one form or another rather than motivating us to undertake responsibility for justice (Shklar, 1990). Indeed, this is a reasonable response, since accidental misfortune is not something we should expect to protect against by changing laws, policies, or institutional arrangements. While well intentioned, these individual stories about accidental misfortune obscure some more fundamental explanations about the causes and conditions of hunger that apply systematically to groups of people.

\section{Structural Background Conditions}

If we explain the causes of food insecurity by referencing the failure of individual responsibility, then we are more likely to ignore the background conditions that contextualize circumstances that constrain individual choice and action. And if these background conditions are obscured then it is much more difficult to identify what needs to be done in order to correct these systemic injustices. In other words, it is unlikely that we will seek to change systemic and structural conditions of poverty and hunger if we cannot see or identify these structural causes in the first place, as well as see how these causes unjustly operate to disadvantage certain populations.

According to Young (2011), structural injustice differs from two other types of injury. A person may be wronged by actions perpetrated by other individuals, as when a person's integrity or self esteem is harmed by a racist comment or a woman is denied employment because of sexist attitudes by someone in a position of authority. Alternatively, a person may be harmed by a specific action or policy implemented by states or institutions. For example, if that person is denied employment because of her age and there is a corporate policy that institutionalizes age discrimination, then she is wronged by an unjust corporate policy. But Young insists that structural injustices do not reduce to 
either of these kinds of wrongs. Structural injustices create conditions of vulnerability for individuals by virtue of the social structural position these individuals occupy. To understand structural injustice requires us to take a "macro" view of society, in which we attempt to bring into focus some general conditions that operate on individuals with diverse life histories, attributes, and goals (Young, 2011, p. 56). These conditions are complex, multiple, large-scale, and typically long-standing circumstances that are attributable to many individuals as well as to public and private institutional policies. The salient feature of these sets of social circumstances is that they operate according to "normal rules and accepted practices" to create vulnerabilities and disadvantages for subgroups (Young, 2011, p. 52). The practical problem I address in the next section is how to convey these kinds of background conditions about food insecurity to ordinary citizens, including the charity worker.

\section{Rewriting the Personal Responsibility Script}

By virtue of its wide and pervasive influence as well as its rhetorical power to subvert and shape our ideas about who is hungry and why, the personal responsibility script qualifies as a master narrative. Elsewhere I have argued that one appropriate way of correcting this kind of narrative is to write or read a counterstory that includes context and particular circumstances of lived experience, especially the identities of those who seek to nourish themselves (Dixon, 2014). In this essay I apply the concept of counterstory in a new way to capture background conditions that contribute to food insecurity. The basic idea of a counterstory originates with Nelson (2001), who describes a counterstory as resisting and responding to oppressive master narratives that deprive individuals and social groups of opportunities to live well. A counterstory contributes in a positive way to repairing oppressive identities by replacing damaging narratives with ones that command respect for individuals and groups. In Nelson's own use of counterstories to repair damaged identities she recommends telling these stories in two steps. The first step is to identify what parts of the master narrative misrepresent persons and situations. The second step involves a retelling of the story to make visible the morally salient details of the master narrative that were suppressed (Nelson, 2001). As I have described above, the personal responsibility script misrepresents a more fundamental explanation of the causes of food insecurity. But in order to make visible what is suppressed by this kind of master narrative we need to retell the story of food insecurity so as to reveal background conditions that specify structural injustices. In other words, in order to correct the personal responsibility script I recommend a counterstory that makes perspicuous these structural background conditions of poverty and hunger and that describes a generalized position of disadvantage that applies to groups (single mothers, fast-food workers, etc.). Most importantly, a counterstory should be one that can match the rhetorical power of the personal responsibility script.

From this perspective let us return to the stories we tell about individual people who are vulnerable specifically to food insecurity. What is it about these stories that will enable us to see how structural injustices operate? An example is the popular documentary film, A Place at the Table (Jacobson \& Silverbush, 2013), which includes several stories of people who experience some degree of food insecurity. One story introduces Barbie, a single mother of two young children in Philadelphia who actively searches for work after losing her job. She aspires to attend college for training and to increase her earning potential, but realizes how impossible this goal is for her now. Her immediate urgent problem is to feed herself and her children. She relies on public assistance to do so, including food stamps, food pantries, and free meal programs for her children. But even so she is barely making ends meet, even when she is eventually employed full-time at a job that pays US $\$ 9.00$ per hour. It seems that being employed at this wage creates further obstacles. Barbie is now US $\$ 2.00$ over the monthly income limit for food stamp eligibility, and her children no longer qualify for the free meal programs they received when she was not working at all.

Why does Barbie's story qualify as a counterstory? Telling Barbie's story in this particular way defies some assumptions of the personal responsibility script we have already discussed. Barbie 
wants to work and she eventually gets a full-time job. So she hardly fits Rep. Fincher's description of a person who is "unwilling to work." Moreover, Barbie's food insecurity is not due to bad luck, misfortune, or some idiosyncratic temporary lapse in her personal responsibility to support herself and her children. The background conditions that the filmmakers use to explain her food insecurity are systemic and structural. They include lack of accessible food or nearby fully stocked supermarkets, difficult and lengthy travel to find these cheaper food markets, low-wage pay scale, eligibility limits for receiving SNAP benefits, and qualifying income levels for children's free meal programs. Most importantly, what the audience of this film should notice is that these conditions operate collectively to disadvantage Barbie and others who occupy the same generalized position (single mothers, working low-income families, etc.). But no one law or policy is actually designed to harm them. In fact, social services are designed to help people like Barbie who are struggling. Even so, the obstacles that constrain Barbie's choices combine to disadvantage her, and these circumstances are beyond her individual ability to control. Additionally, the filmmakers direct our attention to structural background conditions such as U.S. Department of Agriculture (USDA) subsidies and lobbying. We learn, for example, that $84 \%$ of USDA subsidies have gone to mega-farms and agribusiness to support commodity crops such as corn, cotton, soy, wheat, and rice. Not coincidentally, in 2011 agribusiness spent US $\$ 124.7$ million in special interest lobbying, outspent only by oil and gas corporations. As Congress has continued to support the large corporate food industry, it has also gradually decreased funding programs - including SNAP benefits, National School Lunch, housing subsidies, programs for seniors, and Aid to Families with Dependent Children (AFDC) — that support those living at the margins of society (Jacobson \& Silverbush, 2013).

Telling Barbie's story together with this explanatory context directs the viewer's attention to more systemic conditions that are complex, large-scale, and attributable to many individuals, institutions, and public policies. Despite the complexity of this macro view of food insecurity, at least the background conditions are sufficiently articulated so that we can inquire about their ethical justifiability. The deeper and fuller story of hunger revealed by the counterstory makes it possible to ask, "What social and political conditions should change?"

Counterstories can function as a practical strategy for achieving food justice advocacy. In order to do so they should satisfy two conditions. First, a counterstory should correct the damaging master narrative that I am calling the personal responsibility script. Second, a counterstory should position ordinary citizens epistemically to identify structural injustices that contribute to food insecurity, especially those structural conditions of poverty and income inequality that disadvantage populations.

A number of recent documentary films and texts satisfy these main conditions of a counterstory. For example, the documentary film Fed Up (Soechtig, 2013) illustrates the tragedy of childhood obesity. The poignant aspect of this health issue is portrayed by the voices of the children themselves. In spite of their own protestations about how they cannot seem to lose weight and make healthier food choices, the film repositions us to see this not as an individual failure, but as a public policy issue involving an environment of ubiquitous junk food in school lunch programs and in grocery store aisles. The documentary film Inequality for All (Kornbluth, 2013) profiles the structural conditions of inequality by identifying rising costs in housing, health care, higher education, and child care together with stagnating wage increases. These conditions are not presented as inevitable market forces, but as a consequence of corporate profits and lobbying that secure wealth for a few by keeping labor costs and wages down for many. Leonard's (2014) exposé of Tyson Foods can be read with a particular eye to structural conditions that disadvantage contract farmers in the meat industry by a combination of practices that include vertical integration (corporate ownership of the entire meat supply chain), "tournament" ranking systems of pay, debt, bankruptcy, and federally insured lending practices, as well as lobbying by the meat industry to restrict federal regulations intended to protect contract farmers.

These examples are intended for popular audiences, not merely for academics and theorists who 
write about food justice. This makes them ideally suited to the ordinary citizen who, through focusing on the ethically salient features of these narratives, can become alert to those structural conditions that contribute to hunger, poverty, and inequality. In the next section I consider the practical application of counterstories: how they might be used and by whom.

\section{Back to the Food Shelf}

Today the editors of our local newspaper awarded a public "cheer" to the owner of a laundromat and car wash (Cheers and Jeers, 2014). The owner was commended because he treated a homeless man with respect, "a gesture that other people may not have been able to muster" (p. A5). The owner also gave the homeless man a US $\$ 1$ token for being a good customer. The editors concluded, "It was a small gesture but an important one, maintaining the dignity of the homeless man. Wouldn't it be wonderful if everyone treated less fortunate people with kindness and compassion instead of disdain?" (p. A5). Two questions about this story immediately come to mind. First, why is it newsworthy that a person treats a homeless man with respect rather than disdain? This is remarkable behavior only relative to the background assumption that homeless people are undeserving of respect. And second, how does giving the homeless man a US $\$ 1$ token imbue him with dignity? Perhaps this small act of charity by those of us who have something should be welcome by those of us who have nothing. But this relationship of charity does nothing for the dignity of the recipient (see Poppendieck, 1998, chapter eight) Unintentionally, the editors of our local paper demonstrate in the public domain the real need to correct identity-damaging narratives about those who have no place to live and, by extension, those who visit our local food shelf. Los Angeles FEMA local board director Gene Boutillier remarks that the "main political task in dealing with poverty is for people to identify with the poor so they can't be demonized and they can't be discounted and they can't be ignored" (as quoted in Poppendieck, 1998, p. 310). The move toward food justice advocacy begins with a good counterstory that replaces a damaging oppressive narrative with one that commands respect (Nelson, 2001).
In addition, the move toward food justice advocacy begins with the volunteer. Poppendieck (1998) believes that the entry point to advocacy work is the charity worker who is active in hunger relief programs, since these people are already knowledgeable about who is hungry and are poised to challenge unfairness and to address increasing inequalities. There are, of course, national organizations that emphasize public policy work and advocacy as a solution to hunger, such as Bread for the World and the Food Research and Action Center (FRAC). But many local food shelves, ours included, declare a commitment to social justice as part of their mission. This may be interpreted and acted upon in a number of ways. So it makes sense to enlist the volunteers at the food pantry to show a film, lead a book discussion, or form a local food justice committee to inquire how to initiate policy change as part of rewriting the call to charity. Some of us are teachers and can use already existing counterstories or an assignment to write a counterstory as a way of profiling how hunger is structurally caused.

Ideally, a counterstory should inspire ordinary citizens to undertake individual or collective action on behalf of food justice, shaping our moral imaginations about what is possible. We might also insist that counterstories illustrate activist roles for individual action, or collective or coordinated activity to address injustices. For example, the charity worker may come to see possibilities that depend on existing organizations such as church groups, unions, cooperatives, or food policy councils, and how members can act together to initiate change. In this way an ordinary citizen who works for a charitable organization can become more thoughtfully aware of systemic injustices, if not an activist, in order to discharge her responsibility for justice.

The recommendation I make in this viewpoint is a practical one. Many writers have identified the need for political and structural change in order to achieve food justice (Allen, 2010; Allen \& Guthman, 2006; Gottlieb \& Joshi, 2010; Guthman, 2008; Hassanein 2003; Sbicca, 2012). But if practitioners and ordinary citizens are to be usefully directed to become food justice policy advocates, then we should be prepared to answer how they can become advocates. Reading, watching, and reflect- 
ing on counterstories of the kind I describe here epistemically position the food shelf volunteer or the charity worker to see more effectively what systemic conditions need to change. This is merely one mechanism for achieving what Hassanein (2003) believes is crucial to transforming the food system: an informed citizenry.

\section{References}

Allen, P. (2010). Realizing justice in local food systems. Cambridge Journal of Regions, Economy and Society, 3(2), 295-308. http://dx.doi.org/10.1093/cjres/rsq015

Allen \& Guthman. (2006). From "old school" to "farmto-school": Neoliberalization from the ground up. Agriculture and Human Values, 23(4), 401-415. http://dx.doi.org/10.1007/s10460-006-9019-z

Brownell, K. D., \& Warner, K. E. (2009). The perils of ignoring history: Big tobacco played dirty and millions died. How similar is big food? The Milbank Quarterly, 87(1), 259-294. http://dx.doi.org/10. 1111/j.1468-0009.2009.00555.x

Cheers and Jeers. (2014, November 24). Plattsburgh, NY Press-Republican. Editorial page.

Dixon, B. (2014). Learning to see food justice. Agriculture and Human Values, 31(2), 175-184. http://dx.doi.org/10.1007/s10460-013-9465-3

Feeding America. (2014). Hunger in your community. Real stories. Retrieved from http://feeding america.org/hunger-in-america/hunger-in-yourcommunity/real-stories-landing-page.aspx

Gilson, E. (2014). Vote with your fork? Responsibility for food justice. Social Philosophy Today. Advance online publication.

http://dx.doi.org/10.5840/socphiltoday20144215

Gottlieb, R., \& Joshi, A. (2010). Food justice. Cambridge, Massachusetts: MIT Press.

Guthman, J. (2008). Bringing good food to others: Investigating the subjects of alternative food practice. Cultural Geographies, 15(4), 431-447. http://dx.doi.org/10.1177/1474474008094315
Hassanein, N. (2003). Practicing food democracy: A pragmatic politics of transformation. Journal of Rural Studies, 19(1), 77-86. http://dx.doi.org/10.1016/S0743-0167(02)00041-4

Holt-Giménez, E. (2011). Food security, food justice, or food sovereignty? Crises, food movements, and regime change. In A. H. Alkon \& J. Agyeman (Eds.), Cultivating food justice: Race, class, and sustainability (pp. 309-330). Cambridge, Massachusetts: MIT Press.

Jacobson, K., \& Silverbush, L. (Directors). (2012). A place at the table [Documentary]. New York: Magnolia Pictures.

Kornbluth, J. (Director). (2013). Inequality for all [Documentary]. New York: Radius-TWC.

Leonard, C. (2014). The meat racket: The secret takeover of America's food business. New York: Simon \& Schuster.

Nelson, H. L. (2001). Damaged identities, narrative repair. Ithaca, New York: Cornell University Press.

Pollan, M. (2008). In defense of food: An eater's manifesto. New York: Penguin Books.

Poppendieck, J. (1998). Sweet charity: Emergency food and the end of entitlement. New York: Viking Press.

Sbicca, J. (2012). Growing food justice by planting an anti-oppression foundation: Opportunities and obstacles for a budding social movement. Agriculture and Human V alues, 29(4), 455-466. http://dx.doi.org/10.1007/s10460-012-9363-0

Shklar, J. N. (1990). The faces of injustice. New Haven, Connecticut: Yale University Press.

Soechtig, S. (Director). (2013). Fed up [Documentary]. New York: Radius-TWC.

Stolberg, S. G. (2013, September 4). On the edge of poverty, at the center of a debate on food stamps. New York Times, p. A1. http://www.nytimes. $\mathrm{com} / 2013 / 09 / 05 /$ us/as-debate-reopens-foodstamp-recipients-continue-to-squeeze.html

Winne, M. (2008). Closing the food gap: Resetting the table in the land of plenty. Boston, Mass.: Beacon Press.

Young, I. M. (2011). Responsibility for justice. Oxford Political Philosophy. Oxford, UK: Oxford University Press. 